\title{
Effect of Specimen Placement on Model Rock Blasting
}

\author{
Zong-Xian Zhang ${ }^{1}$ (1) $\cdot{\text { Li Yuan } \mathrm{Chi}^{2} \cdot \text { Qingbin Zhang }}^{3}$
}

Received: 5 November 2020 / Accepted: 16 April 2021 / Published online: 29 April 2021

(c) The Author(s) 2021

\begin{abstract}
Small-scale model blasting plays an important role in understanding mechanism of rock fragmentation by blasting and improving blast technology in rock and mining engineering. Because a specimen (or model) often needs to be placed on either a ground or another material in model blasting, an additional interface appears between the specimen and the ground (or material), compared with an engineering blast that does not have such an interface. In this paper, four model blasts with high-speed photography were presented. The results showed that: (1) as the impedance of a rock specimen was smaller than that of the ground material, the specimen was thrown up and a certain amount of kinetic energy was brought with such a bounce. Thus, this placement should be avoided in model blasts. (2) As a rock specimen was placed on three blocks of the same type of rock as the specimen the specimen was not bounced up during blasting. Correspondingly, no kinetic energy was induced by specimen bounce. Therefore, this placement is recommended for model blasting. If very high specific charge must be used in model blasting, the above-recommended method will not work well due to possible breakage of the base material during blasting. In this case, the rock specimen can be placed on a material with smaller impedance than that of the rock specimen so that specimen bounce can be reduced. Accordingly, such a possible specimen bounce should be estimated by stress wave analysis.
\end{abstract}

Keywords Rock blasting $\cdot$ Small-scale model $\cdot$ Boundary condition $\cdot$ Kinetic energy $\cdot$ Fragmentation

\section{Introduction}

A good solid explosive can convert energy at a rate of $10^{10}$ watts per square centimeter of its detonation front (Fickett and Davis 2000). Upon detonation, an explosive can produce a pressure over $20 \mathrm{GPa}$ and a temperature above $3000{ }^{\circ} \mathrm{C}$. Explosives are so powerful that rock blasting has been used in hard rock mining and hard rock engineering for over one century. However, up till now rock blasting has been dominated by empirical design, resulting in considerable mineral loss, poor safety, high vibrations, explosive wastage, and induced seismic events (Zhang 2016). One of the main reasons for the empirical design is that the mechanism of rock fragmentation by blasting has not been well-understood so

Zong-Xian Zhang

zongxian.zhang@oulu.fi

Oulu Mining School, University of Oulu, Oulu, Finland

2 State Key Laboratory of Explosion Science and Technology, Beijing Institute of Technology, Beijing, China

3 School of Civil Engineering, Changsha University of Science and Technology, Changsha, China far. To make a blast design more scientific and a blast operation more economic, more efficient, and less environmentdisturbed, it is necessary to carry out various model blasts.

A great number of model blasts have been carried out for several decades (e.g., Field and Ladegaard-Pedersen 1971; Bergman et al. 1973; Fourney et al. 1974, 1981, 1993, 2006; Dally et al. 1975; Bhandari 1979; Rustan 1995; Nie et al. 2000; Nie and Olsson 2001; Moser and Grasedieck 2004; Katsabanis et al. 2006, 2014; Tilert et al. 2007; Johansson and Ouchterlony 2013; Onederra et al. 2013; Sun 2013; Fourney 2015; Liu et al. 2018; He et al. 2018; Chi et al. 2019a, b, c; Yang et al. 2019; Zhang et al. 2020a, b, 2021; Mao et al. 2020). In various model blasts including those mentioned above, the constraint condition to a blasting specimen is usually different from that in engineering blasting, giving rise to that the results of a model blast are different from the ones of an engineering blast to a certain extent. The first discrepancy between an ordinary model blast and an engineering one is that there are often more free surfaces in the model blast than in the engineering blast. To minimize the effect of multiple free surfaces on the result in model blasts, 
mortar models were employed in which an ordinary rocklike specimen was tightly enclosed by a larger volume of mortar material (e.g., Johansson and Ouchterlony 2013; Sun 2013; Katsabanis et al. 2014). In this way, the stress wave reflection from the interfaces between the rock-like specimen and the larger volume of mortar can be avoided if the characteristic impedances of the specimen and the larger mortar are matched each other, even though the wave reflection from the free surfaces of the larger mortar still exists.

Besides the first discrepancy, the second one between a model blast and an engineering blast is that there is an interface between the rock (or rock-like) specimen and the ground (or another object) on which the specimen is placed in the model blast, but such an interface does not exist in the engineering blast. Compared with the engineering blast lacking such an interface, the interface in the model blast will cause stress wave reflection (unless the impedances of both the specimen and the ground are equal to each other). Correspondingly, a certain amount of explosion energy will be carried by the reflected wave, and additional movement of the specimen will be induced. As a result, fracture and fragmentation in the model blast might be affected more or less, depending on the conditions of the interface, i.e. the placement of the specimen. Unfortunately, the effect of specimen placement on blasting results in model blasting has not been investigated up till now. Accordingly, this paper is to demonstrate that a rock specimen can be thrown up during blasting if the placement of the specimen is not correct. Then, simple stress wave theory is used to analyze the movement of a blast model placed on a floor with two different material impedances. Finally, proper or correct methods for placing rock specimens in model blasting are suggested.

\section{Model Blasts}

\subsection{Rock, Explosives and Specimen Placement}

Four model blasts performed in the explosion chamber of Beijing Institute of Technology are presented in the following, with high-speed camera photographs. The experimental method and fracture result of three specimens presented in this study have been reported in Chi et al. (2019a, b, c), but the throw and movement of these specimens have not been reported before. This study will use the photographic result of the three blasts. In addition, the blast result of another specimen that was not reported at all will be used in this study. The detailed blast experiments and fracture results of the three specimens can be found in the above references. The basic parameters of these four blasts are given in Table 1.

The experimental setup of these four blasts is shown in Fig. 1. In this figure, except for the floor of the explosion chamber and the diameter of blasthole, the other parameters such as borehole length, detonator length, stemming length, and steel tubes are in scale (e.g. the each side of the cubic granite block is $400 \mathrm{~mm}$ ). The rock was a granite from Fangshan in Beijing, China and its density and average primary wave (P-wave) velocity were $2.74 \mathrm{~g} / \mathrm{cm}^{3}$ and $4200 \mathrm{~m} / \mathrm{s}$, respectively. The density and the $\mathrm{P}$-wave velocity of the steel plate and tube (made of AISI 1045 steel) were $7.87 \mathrm{~g} / \mathrm{cm}^{3}$ and $5907 \mathrm{~m} / \mathrm{s}$, respectively. The explosives were PETN and TNT. The explosion energy, the density and the detonation velocity of the TNT were $4184 \mathrm{~J} / \mathrm{g}, 1.6 \mathrm{~g} / \mathrm{cm}^{3}$, and $6800 \mathrm{~m} / \mathrm{s}$, respectively; the corresponding parameters of the PETN were $5810 \mathrm{~J} / \mathrm{g}, 0.9 \mathrm{~g} / \mathrm{cm}^{3}$, and $5200 \mathrm{~m} / \mathrm{s}$, respectively (Chi et al. 2019c). The blastholes of all specimens were stemmed by cement grout, the cylindrical specimens were $300 \mathrm{~mm}$ in length and $228 \mathrm{~mm}$ in diameter, and the cubic specimen

Table 1 Parameters related to explosive and experimental condition

\begin{tabular}{|c|c|c|c|c|c|c|c|c|}
\hline Specimen & $\begin{array}{l}\text { Constraint to } \\
\text { specimen }\end{array}$ & $\begin{array}{l}\text { Base material } \\
\text { below Speci- } \\
\text { men }\end{array}$ & Explosive (g) & $\begin{array}{l}\text { Speed of } \\
\text { photography } \\
\text { (frames/s) }\end{array}$ & $\begin{array}{l}\text { Size of each } \\
\text { pixel }(\mathrm{mm})\end{array}$ & $\begin{array}{l}\text { Resolution } \\
(\text { pixel } \times \text { pixel })\end{array}$ & $\begin{array}{l}\text { Ratio of speci- } \\
\text { men imped- } \\
\text { ance to base } \\
\text { impedance }\end{array}$ & Note \\
\hline S1 (cylinder) & $\begin{array}{l}\text { Steel tube with } \\
\text { grout }\end{array}$ & Steel plate & $\begin{array}{c}10.5 \text { g TNT; } \\
\text { decoupled } \\
\text { charge }\end{array}$ & 10,000 & 0.87 & $896 \times 848$ & $<1$ & Not reported \\
\hline S2 (cylinder) & $\begin{array}{l}\text { Steel tube with } \\
\text { grout }\end{array}$ & Steel plate & $\begin{array}{l}5.47 \text { g PETN; } \\
\text { decoupled } \\
\text { charge }\end{array}$ & 10,000 & 0.76 & $896 \times 848$ & $<1$ & $\begin{array}{l}\text { S2 in Chi et al. } \\
\text { (2019c) }\end{array}$ \\
\hline S3 (cylinder) & No & $\begin{array}{c}3 \text { granite } \\
\text { blocks }\end{array}$ & $\begin{array}{c}5.5 \text { g PETN, } \\
\text { decoupled } \\
\text { charge }\end{array}$ & 20,000 & 0.47 & $704 \times 520$ & 1 & $\begin{array}{l}\text { S5 in Chi et al. } \\
(2019 \mathrm{c})\end{array}$ \\
\hline S4 (block) & No & $\begin{array}{l}3 \text { granite } \\
\text { blocks }\end{array}$ & $\begin{array}{l}12 \text { g PTEN; } \\
\text { full charge }\end{array}$ & 75,000 & 0.68 & $256 \times 304$ & 1 & $\begin{array}{l}\text { S6 in Chi et al. } \\
\text { (2019a) }\end{array}$ \\
\hline
\end{tabular}


(a)

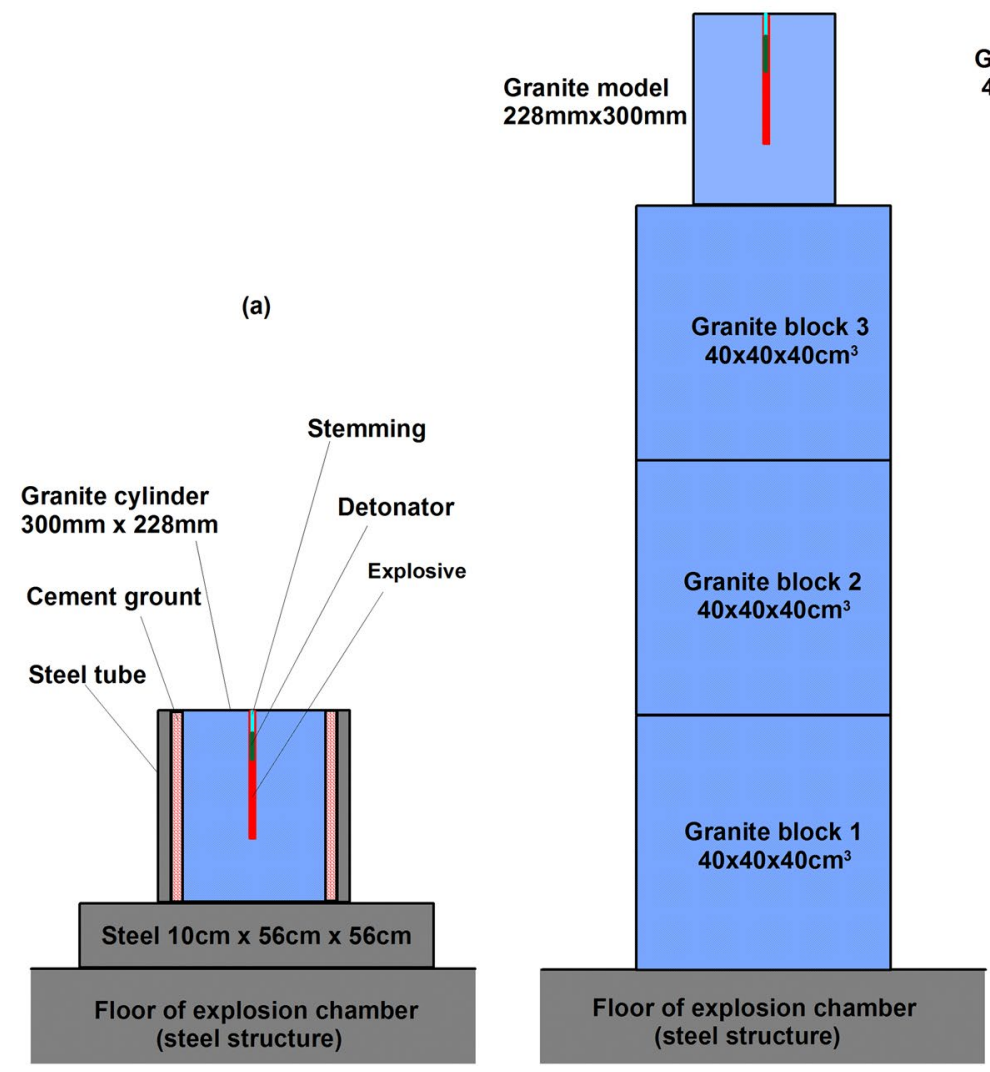

(b) (c)

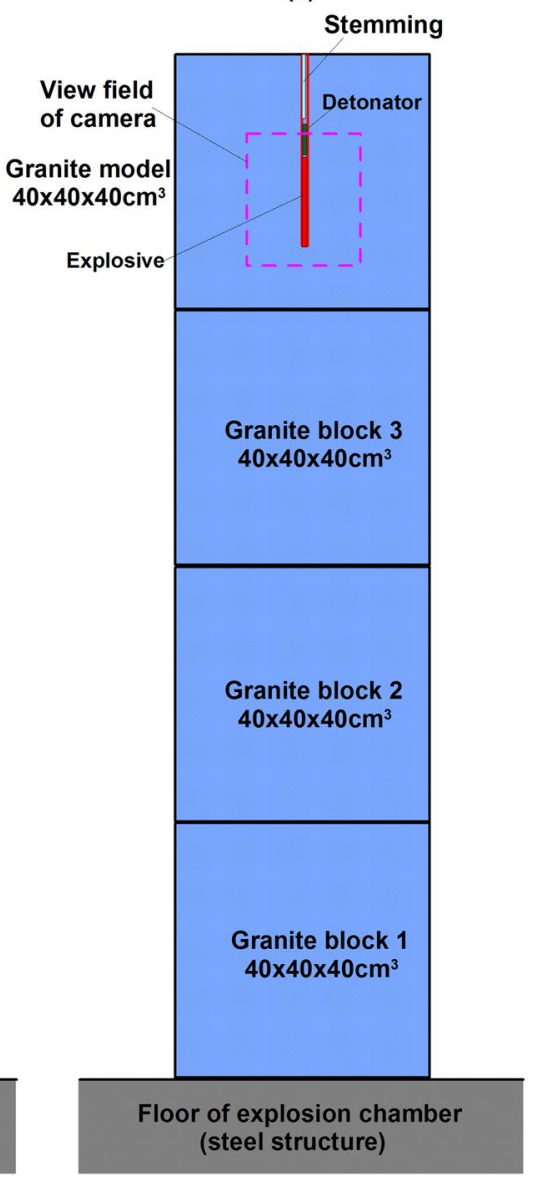

Fig. 1 Experimental setup. a Cylindrical granite specimens S1 and S2 fully confined by steel tube placed on the steel plate on the floor of the blast chamber; $\mathbf{b}$ cylindrical granite specimen S3 placed on the pile of three granite blocks on the floor of the blast chamber; c cubic

was in the size of $400 \times 400 \times 400 \mathrm{~mm}^{3}$. These sizes are also shown in Fig. 1.

During blasting, a high-speed camera named Photron Fastcam SA5 was used to film the blasting process as reported in Chi et al. (2019a, b). The camera was fixed at a place outside of the explosion chamber but close to the bulletproof window. During each blast, the display area of the photography of the camera was a constant. Thus, any movement of a specimen or a fragment can be determined using the photographs at different times taken from the camera.

\subsection{Rock Specimens Placed on Steel Plate During Blasting}

Two specimens S1 and S2 shown in Fig. 1a and Table 1 were involved. Each cylindrical granite specimen was placed inside a steel tube, and the gap between the rock specimen and the steel tube was grouted. After a sufficient curing time, the whole specimen was placed on a steel plate situated on rock specimen $\mathrm{S} 4$ placed on the pile of three granite blocks on the floor of the blast chamber. The view field of the camera was $150 \mathrm{~mm}$ wide and $180 \mathrm{~mm}$ high in $\mathbf{c}$

the steel floor of the explosion chamber, as shown in Fig. 1. Since the characteristic impedance (product of density and sonic velocity) of either the rock or the grout is much smaller than that of the steel, it is assumed that the impedance of the whole specimen including the rock cylinder, the steel tube and the grout is smaller than that of the steel plate or the steel floor.

Nine pictures from the camera for S1 are shown in Fig. 2 where the time zero means the initiation time of detonation. The sizes of the steel plate beneath the rock specimen and above the floor of the explosion chamber were $100 \times 560 \times 560 \mathrm{~mm}^{3}$. The floor of the chamber was made of steel. The outer and inner diameters of the steel tube were $300 \mathrm{~mm}$ and $268 \mathrm{~mm}$, respectively. The gap between the rock specimen and the steel tube was $20 \mathrm{~mm}$.

The borehole was $150 \mathrm{~mm}$ long and ended at the center of the specimen. The explosive was charged from the bottom of the borehole with $83 \mathrm{~mm}$ charge length and $10.5 \mathrm{~g}$ explosive. The diameter of the explosive charge and that 


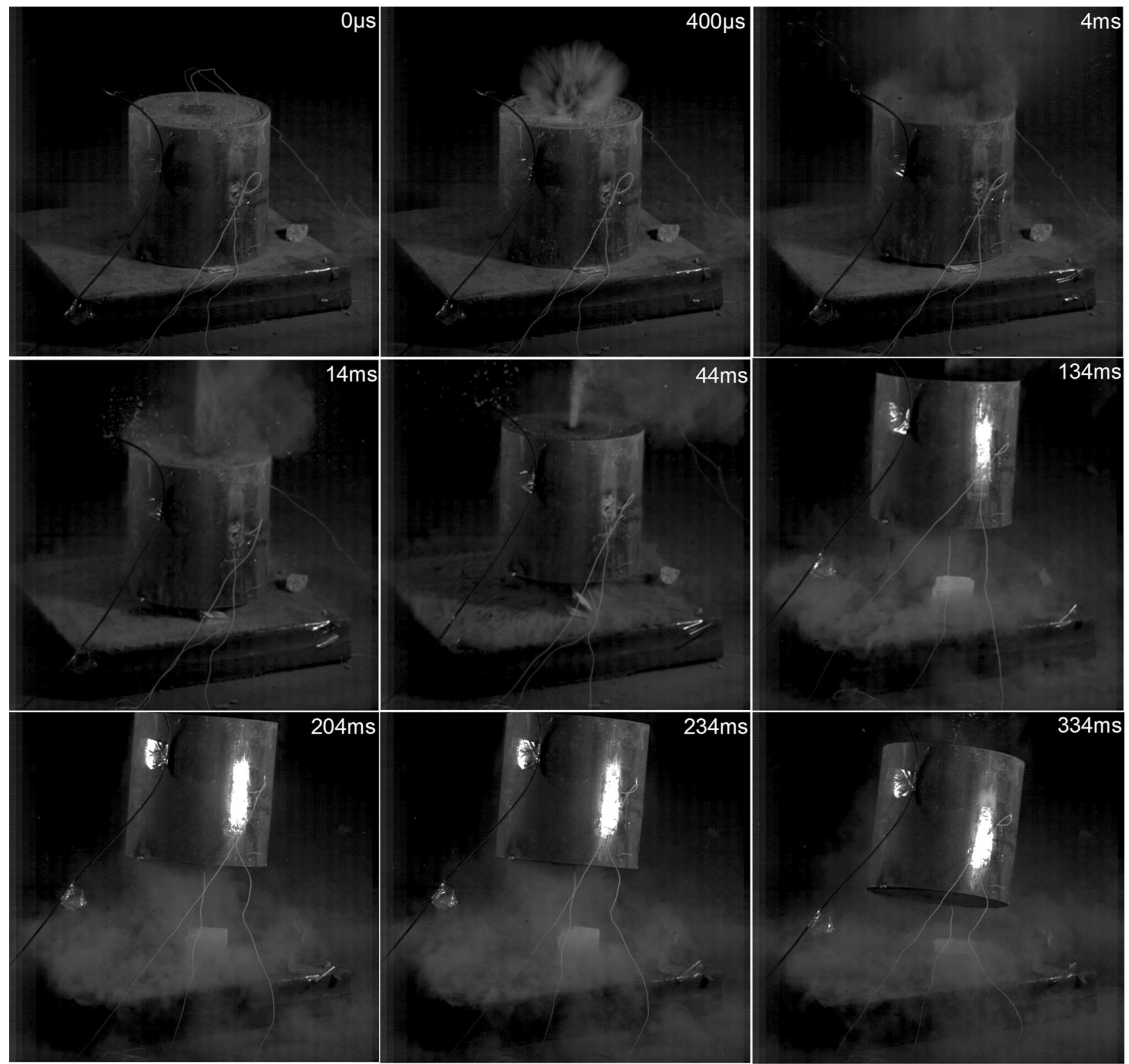

Fig. 2 Photographs from high-speed camera for S1. The detonation was initiated at $0 \mu \mathrm{s}$

of the borehole were equal to $10 \mathrm{~mm}$ and $14 \mathrm{~mm}$, respectively. The stemming was $67 \mathrm{~mm}$ long and the material of stemming was a wet grout. A detonator was placed at the top of the explosive, a pressed TNT. The density of the filled material in the gap was $2.2 \mathrm{~g} / \mathrm{cm}^{3}$.

The masses of the steel tube, the rock specimen (only rock), and grout material were $33.7 \mathrm{~kg}, 33.5 \mathrm{~kg}$, and $10.3 \mathrm{~kg}$, respectively, i.e. the mass of whole specimen including rock, grout and tube was $77.5 \mathrm{~kg}$. As shown in Fig. 2, the whole specimen was thrown upward until the maximum height, and then it fell down.
The second specimen $\mathrm{S} 2$ had similar constraint condition to $\mathrm{S} 1$. The main difference between the two blasts of $\mathrm{S} 1$ and S2 was that they had different explosive charges. Figure 3 shows nine pictures of S2 from the high-speed camera. Similar to $\mathrm{S} 1, \mathrm{~S} 2$ was also thrown up during blasting.

\subsection{Rock Specimens Placed on Three Rock Blocks During Blasting}

This case includes two specimens S3 and S4. S3 was a cylindrical granite specimen and S4 a cubic granite. During 

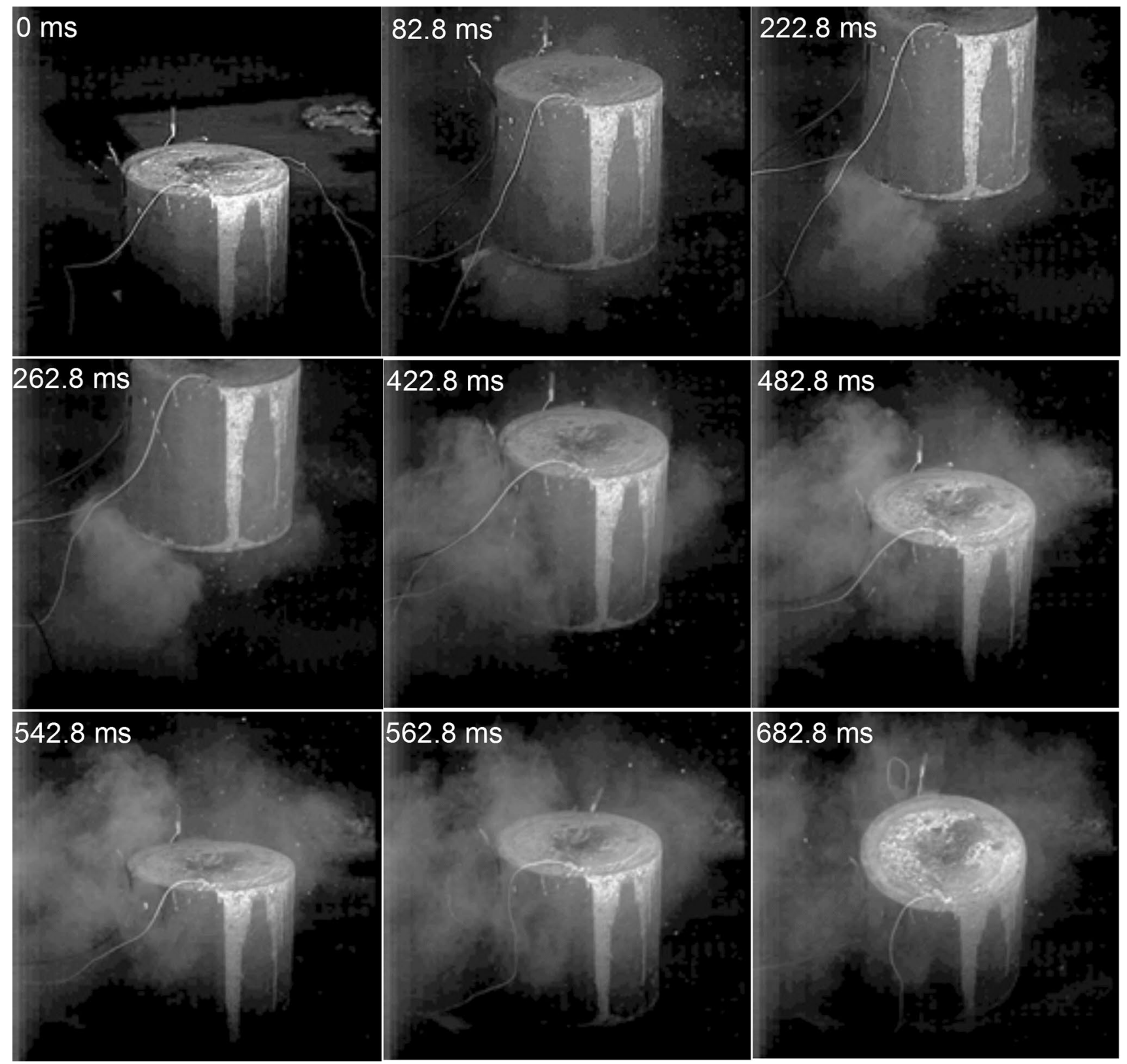

Fig. 3 Photographs of S2 from high-speed camera. The detonation was initiated at $0 \mu \mathrm{s}$

blasting either S3 or S4 was placed on three rock blocks that were piled on the floor of the explosion chamber, as shown in Fig. 1b, c. There was no confinement to the specimens. The blocks and the rock specimens were manufactured from the same type of granite in the quarry. The sizes and other parameters of S3 are indicated in Fig. 1 and Table 1.

A total of twelve photographs for S3 are shown in Fig. 4. As mentioned earlier, each photograph from the high-speed camera has a constant area of screen display, so the movement of the specimen can be seen clearly from the pictures. On the surface of S3 three " $x$ " were marked in order to judge whether the specimen had moved or not. Obviously, the three
" $x$ " were nearly at the same positions before and at the time $3.75 \mathrm{~ms}$. From the time $35 \mathrm{~ms}$ on, the fragment with three " $x$ " started to move up. At time $50 \mathrm{~ms}$, the fragment with " $x$ " moved up by a certain distance. However, at $3.75 \mathrm{~ms}$ the specimen had been completely destroyed into independent fragments, i.e. the upward movement of the entire specimen did not exist in S3. Even though some upward movement was visible in the pictures at $35-50 \mathrm{~ms}$, such movement did not influence rock fracture and fragmentation.

At $35 \mathrm{~ms}, 37.5 \mathrm{~ms}$ and $50 \mathrm{~ms}$, three " $x$ " symbols were still visible, and the relevant fragment moved higher and rotates. In last two pictures at $37.5 \mathrm{~ms}$ and $50 \mathrm{~ms}$, most 

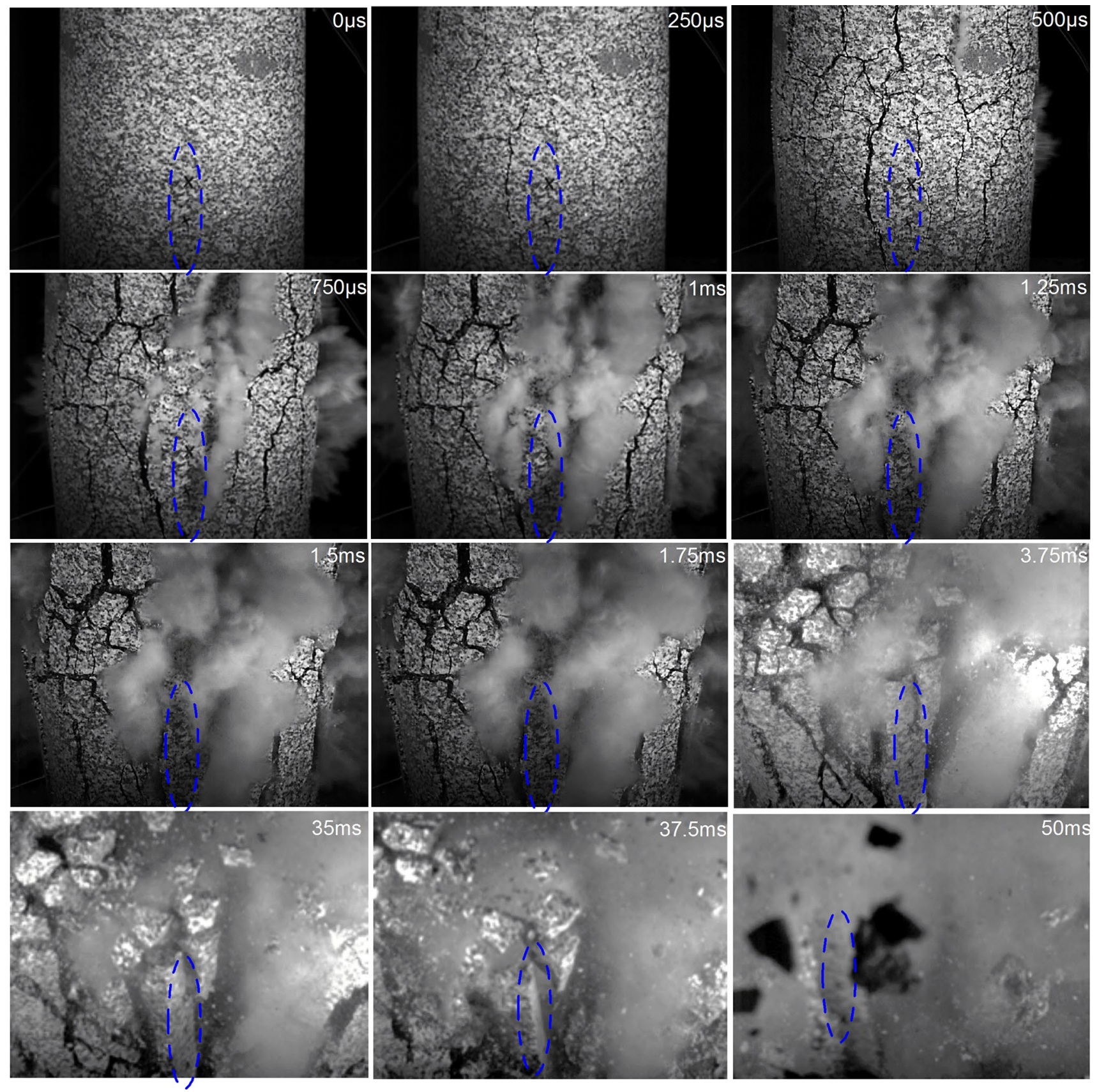

Fig. 4 High-speed photographs of S3. The detonation was initiated at $0 \mu \mathrm{s}$

fragments had moved out of the camera's window areathe area of each high-speed photograph.

Similar to S3, S4 was placed on three rock blocks during blasting. Its sizes and other parameters are indicated in Fig. 1 and Table 1. The selected high-speed photographs are shown in Fig. 5. Obviously, the vertical movement of S4 is nearly zero at all pictures including last one at time $13.3 \mathrm{~ms}$. Note that the picture at $798 \mu \mathrm{s}$ after the initiation of detonation shows the main cracks have already been visible.

\section{Results Concerning Specimen Placement}

\subsection{Throw of Rock Specimen}

As shown in Figs. 2 and 3, two specimens S1 and S2 were thrown up at least $300 \mathrm{~mm}$ high during blasting. On the contrary, as indicated in Figs. 4 and 5, two specimens S3 and $\mathrm{S} 4$ were not thrown up before they were fragmented, e.g. before $1.5 \mathrm{~ms}$ after detonation was initiated. The major reason was that $\mathrm{S} 1$ and $\mathrm{S} 2$ were placed on a steel plate 


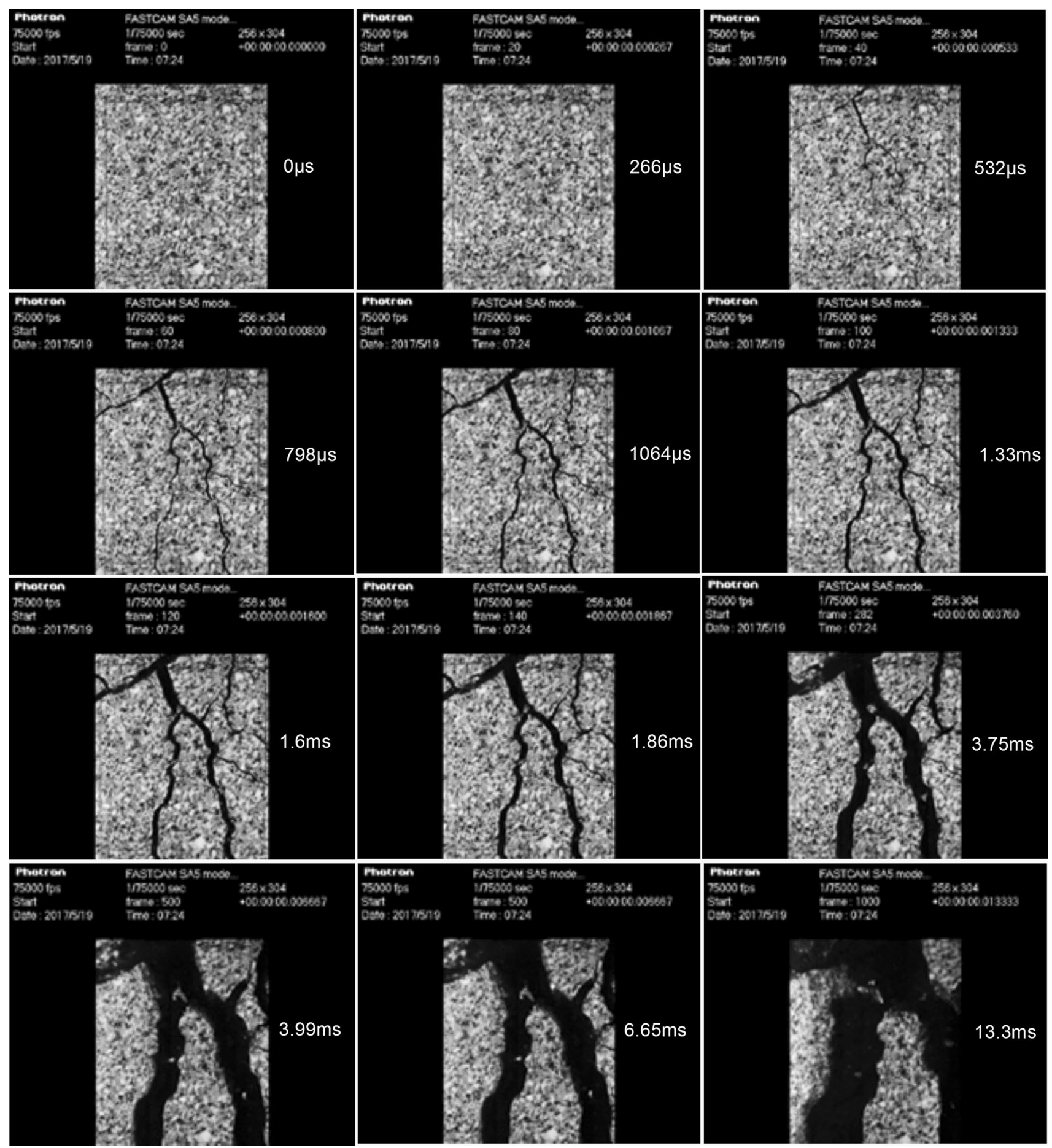

Fig. 5 High-speed photographs of S4. Detonation started at $0 \mu$ s. In these photos only part of specimen was displayed, as shown in Fig. 1

while S3 and S4 on the pile of three granite blocks, and the impedance of $\mathrm{S} 1$ or $\mathrm{S} 2$ was smaller than that of the steel plate while the impedance of S3 or S4 was equal to that of the granite blocks. A detailed analysis will be performed in next section.

\subsection{Throw Velocity of Rock Specimen}

Since the high-speed camera and each specimen were placed at two fixed positions under a constant focus, all photographs of each specimen had a constant area of display screen, as 
mentioned earlier. Thus, the velocities of the specimen movement can be approximately determined by measuring the distance of specimen movement on the photographs at different times. The measurement result of $\mathrm{S} 1$ and $\mathrm{S} 2$ is shown in Fig. 6. From Fig. 6a it can be found that the maximum velocity is approximately $2.1 \mathrm{~m} / \mathrm{s}$ at around $5 \mathrm{~ms}$ for S1. Since the high-speed photography stopped at $375 \mathrm{~ms}$, there were no data available after that time in Fig. 6a.

Compared with S1, S2 had a much longer photographing time. In Fig. 6b, S2 was thrown up first $(A-B-C)$. At point $C$, the specimen was bounced up to the highest position with a velocity of zero. Then the specimen fell down $(C-D)$ and landed on the steel plate at point $D$. And then it was thrown up from point $D(D-F$ and after $F)$ until the velocity became zero and then it fell down again. At point $G$ the specimen landed on the steel plate again (second landing) and then almost immediately it was bounced up again. After then the third landing certainly happened, but the high-speed photography did not record it. It is difficult to confirm the fourth landing, but it can be neglected even though it might exist since the peak velocity of the specimen decreases rapidly, as shown in Fig. 6b. The curve from $G$ to $H$ represents the third bounce of the specimen. From Fig. $6 \mathrm{~b}$ we can find the moving velocities of the specimen $\mathrm{S} 2$ at points $B, D, F, G$ and $H$ are approximately equal to $2.5 \mathrm{~m} / \mathrm{s},-2.9 \mathrm{~m} / \mathrm{s}, 2.0 \mathrm{~m} / \mathrm{s}$, $-1.1 \mathrm{~m} / \mathrm{s}$, and $0.8 \mathrm{~m} / \mathrm{s}$, respectively.

As shown in Figs. 4 and 5 and described in Sect. 3.1, there was almost no vertical movement for specimens $\mathrm{S} 3$ and S4 during blasting, i.e. the bounce velocity of either S3 or S4 was approximately zero.

\subsection{Kinetic Energy Relevant to Specimen Throw}

Since the high-speed photography of S1 stopped at time $375 \mathrm{~ms}$, the photographs showing the landing and possible secondary throw-up of the S1 were lacking. However, it seems from Fig. 7 that the movement of S1 has the same track as S2. Thus, we mainly determine the kinetic energy relevant to the vertical movement of S2. As described earlier, from Fig. 6 (and Fig. 7) we can find the throw velocities of specimen $\mathrm{S} 2$ at points $B, D, F, G$ and $H$ are approximately equal to $2.5 \mathrm{~m} / \mathrm{s},-2.9 \mathrm{~m} / \mathrm{s}, 2.0 \mathrm{~m} / \mathrm{s},-1.1 \mathrm{~m} / \mathrm{s}$, and $0.8 \mathrm{~m} / \mathrm{s}$, respectively. According to the description in Sect. 3.2, there were three times of landing for $\mathrm{S} 2$, but the third landing was not recorded. According to Fig. $6 \mathrm{~b}$, it can be assumed that the velocity of the third landing is equal to the throw velocity at point $\mathrm{H}$, i.e. $-0.8 \mathrm{~m} / \mathrm{s}$. Thus, the three landing velocities of $\mathrm{S} 2$ are $-2.9 \mathrm{~m} / \mathrm{s},-1.1 \mathrm{~m} / \mathrm{s}$ and $-0.8 \mathrm{~m} / \mathrm{s}$ respectively, and the kinetic energies corresponding to the first, second and third landing are $E_{\mathrm{k} 11}, E_{\mathrm{k} 12}$, and $E_{\mathrm{k} 13}$, respectively, as follows:

$E_{\mathrm{k} 11}=\frac{1}{2} m \times 2.9^{2}=\frac{1}{2} \times 77.5 \times 8.41=326 J$,

$E_{\mathrm{kl} 2}=\frac{1}{2} m \times 1.1^{2}=\frac{1}{2} \times 77.5 \times 1.21=47 \mathrm{~J}$,

$E_{\mathrm{kl} 3}=\frac{1}{2} m \times 0.8^{2}=\frac{1}{2} \times 77.5 \times 0.64=25 J$.

Here $m$ is the mass of the specimen. Notice that all of these kinetic energies do not exist in engineering blasts such as blasts in mining and tunneling since the interface between the rock specimen and the base in the model blasts does not exist at all in the engineering blasts.

Among these kinetic energies, only the $E_{\mathrm{kl} 1}$ of the first landing results from the explosion energy, while the other two kinetic energies are converted between the throwrelated kinetic energy and the gravitational potential
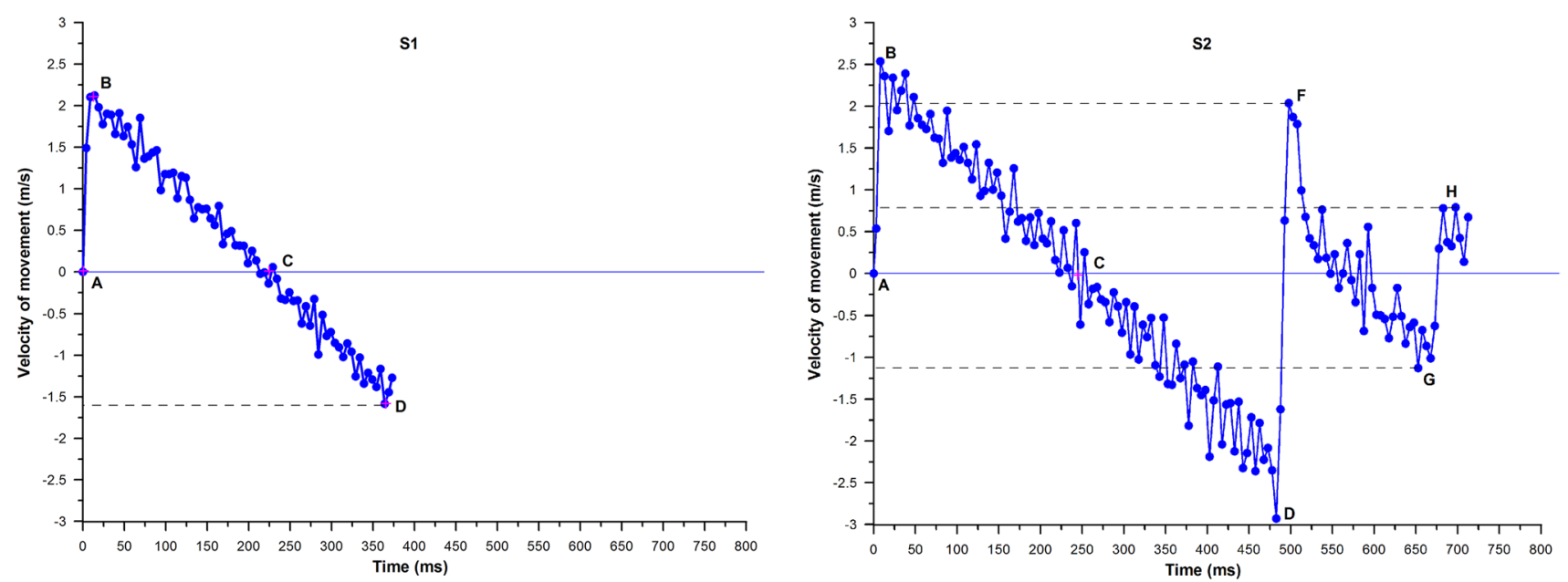

Fig. 6 Vertical velocity of granite specimen vs time after initiation of detonation (at time zero). a S1; b S2 
Fig. 7 Velocity of specimen movement vs time for S1 and S2

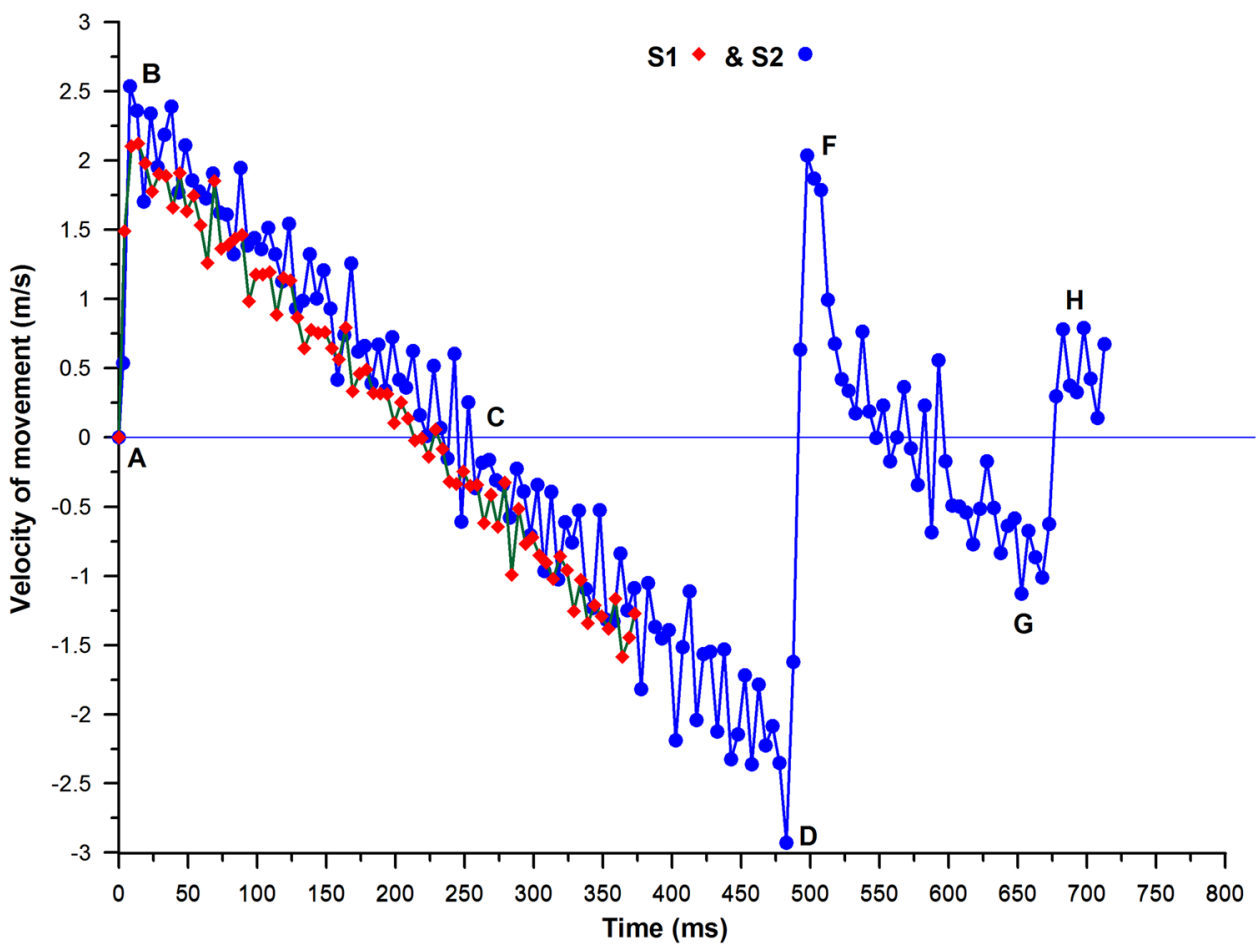

energies. According to the parameters of the TNT explosive in Sect. 2.1, the explosive energy of S2 is equal to:

$E_{\text {expl }}=5810\left(\frac{J}{g}\right) \times 5.5 g=31955 J$.

Thus, the ratio of the kinetic energy due to the first landing of $\mathrm{S} 2$ to the explosion energy is equal to:

$\frac{E_{\mathrm{kl1}}}{E_{\mathrm{expl}}}=\frac{326}{31955}=1.0 \%$.

Although this ratio is small in value, the kinetic energy may not be ignorable. The reason is that the energy efficiency itself in rock blasting is very low (Langefors and Kihlström 1963; Sanchidrián et al. 2007; Ouchterlony et al. 2004; Zhang 2016). For example, only 1-6\% explosive energy is used in rock fragmentation according to the measurements (Sanchidrián et al. 2007). In this sense, one percent of explosive energy certainly plays a role in rock fragmentation.

Moreover, notice that many rocks are composed of one crystal or multiple crystals (such as calcite and quarts). The measured surface energy of calcite was $0.35 \mathrm{~J} / \mathrm{m}^{2}$ (Santhanam and Gupta 1968) and that of quarts varied from 0.41 to $1.03 \mathrm{~J} / \mathrm{m}^{2}$ under room temperature and dry condition (Brace and Walsh 1962). Assume that average surface energy of the crystals in various rocks is $1 \mathrm{~J} / \mathrm{m}^{2}$, we can find that $326 \mathrm{~J}$ energy may create $326 \mathrm{~m}^{2}$ new surface area in rocks. Evidently, this amount of energy cannot be neglected in model blasting.

Note also that although S1 and S2 have different explosive energies, the maximum velocities of the two specimens are nearly same. Since the rock of S1 was fragmented but that of S2 was not seriously fragmented, lower percent of explosive energy must have been used in throwing $\mathrm{S} 1$ than that used in moving $\mathrm{S} 2$.

Compared with the kinetic energies of S1 and S2 discussed above, the kinetic energies of S3 and S4 are zero, since their movement velocities are nearly zero, as described in aforementioned section.

\subsection{Role of Rock Blocks Beneath the Specimen}

As mentioned earlier, S3 and S4 were placed on three granite blocks during blasting, and their charge centers were at $121 \mathrm{~mm}$ from their bottoms. In either specimen, when the P-wave from blasting traveled from the specimen to the three blocks, the wave would be reflected from the floor and come back to the specimen. This process will take the time:

$t=\frac{2 \times 1.2+0.121}{4200}=6 \times 10^{-4} \mathrm{~s}=600 \mu \mathrm{s}$.

Figures 4 and 5 show that main cracks on the front surfaces of both specimens had been already formed before $600 \mu$ s since the detonators were initiated. At the same time, 
gases had started to escape out of one surface crack in S3. This indicates that the influence of the reflected wave from the floor on the formation of crack network might be limited or it can be neglected. One reason is that the attenuation of stress waves is often great in either small laboratory rock specimens or field rock masses (Zhang 2016). Moreover, as described above, there was no specimen throw in S3 and S4. In other words, no kinetic energy due to specimen throw was involved in S3 and S4. In brief, the three rock blocks piled together is long enough to largely reduce the effect of the reflected wave from the floor on rock fracture and fragmentation in these model blasts.

\section{Analysis}

Model blasting is carried out mostly in a blast chamber, but sometimes outside of a laboratory room such as an open field. In most cases, blast models, either rock or rock-like materials such as concrete and cement, are placed on the ground of the blast chamber, as shown in Fig. 1a. The models are either cylindrical or cubic and they often have free surfaces in lateral sides. In order to simplify the analysis, it is assumed that (1) the explosive charge is concentrated at the center of the model and the length of the P-waves caused by blasting in the model is short, (2) such P-waves in the model are approximately elastic compressive waves, and (3) the S-waves and Rayleigh waves either caused by blasting or induced by an inclined incidence of P-waves on a free surface are neglected. According to one-dimensional stress wave theory (Kolsky 1963; Johnson 1972; Wang 2007; Zhang 2016), as one elastic wave propagates from one material, defined as the first material, with stress $\sigma_{I}$, particle velocity $v_{I}$, density $\rho_{1}$ and wave velocity $c_{1}$ to another, defined as the second material, with density $\rho_{2}$ and wave velocity $c_{2}$, the stress $\sigma_{R}$ and particle velocity $v_{R}$ of the reflected wave in the first material are equal to:

$\sigma_{R}=R_{12} \sigma_{I}$,

$v_{R}=-R_{12} v_{I,}$

where $R_{12}$ is called reflection coefficient and it is equal to:

$R_{12}=\frac{1-\xi_{12}}{1+\xi_{12}}$,

where $\xi_{12}$ is the ratio of the characteristic impedance of the first material to that of the second one, and it is defined as:

$\xi_{12}=\frac{\rho_{1} c_{1}}{\rho_{2} c_{2}}$.

These equations will be used to analyze two different cases in the following.

\subsection{Characteristic Impedance of the Ground Greater Than That of the Model}

This case is shown in Figs. 8 and 9 where $\rho_{2} c_{2}>\rho_{1} c_{1}$. S1 and $\mathrm{S} 2$ belong to this case. Here the model is taken as the first material and the ground as the second one, and their densities and P-wave velocities are $\rho_{1}, c_{1}$ and $\rho_{2}, c_{2}$, respectively. Since blast models are usually either cylindrical or cubic and the explosive charge is at the center of the models, the stress wave propagation in the horizontal direction is approximately symmetric. Accordingly, the wave reflection from the lateral surfaces will be not considered in the following analysis, so that the stress wave analysis is focused on the vertical direction.

At the moment shown in Fig. 8, the front of the P-wave from the detonation is arriving at the corners of the model, and its end coming to the position where the smaller dashed circle is located. There are two reflected waves from $A B$ and DC. Look at the first reflected wave from $A B$ in the area enclosed by AGBNEMA in the upper part of the model. This wave with amplitude $\sigma_{A B}$ and particle velocity $v_{A B}$ is formed by the reflection of the original wave with amplitude $\sigma_{I}$ and particle velocity $v_{I}$. As a wave is reflected from a free surface, we get that the reflection coefficient $R_{12}=-1$ according to Eq. 8 (the specimen is material 1 and the air is material 2). Thus, from Eqs. 5 and 6 we get:

$\sigma_{A B}=-\sigma_{I}$,

$v_{A B}=v_{I}$.

This result means that the particle velocity in the reflected wave has the same direction as the original wave, i.e. the particles move upward in the reflected wave from AB.

Then look at the second reflected wave from DC in the area enclosed by DQFRCHD in the lower part of the model. This wave with amplitude $\sigma_{D C}$ and particle velocity $v_{D C}$ is formed by the reflection of the original wave with amplitude $\sigma_{I}$ and particle velocity $v_{I}$ from the interface between the model and the floor. In this case $\left(\rho_{2} c_{2}>\rho_{1} c_{1}\right)$, from Eqs. 5-8 we have

$0<R_{12}<1$,

$\sigma_{D C}=R_{12} \sigma_{I}$,

$v_{D C}=-R_{12} v_{I}$.

This result indicates that the reflected wave from DC enclosed by DQFRCHD is still a compressive wave and the particles in this wave move upward, opposite to the direction of the original compressive wave. Evidently, in the two reflected waves, i.e. the two areas AGBNEMA and DQFRCHD, the particles move upward in the model. With 
Fig. 8 Stress wave propagation in the model-ground system when the front of the P-wave just arrives at the corners $A, B$, $C$, and $D$ of the model under the condition $\rho_{2} c_{2}>\rho_{1} c_{1}$. The end of the $\mathrm{P}$-wave is arriving at $I, G$, $J, L, H$ and $K$

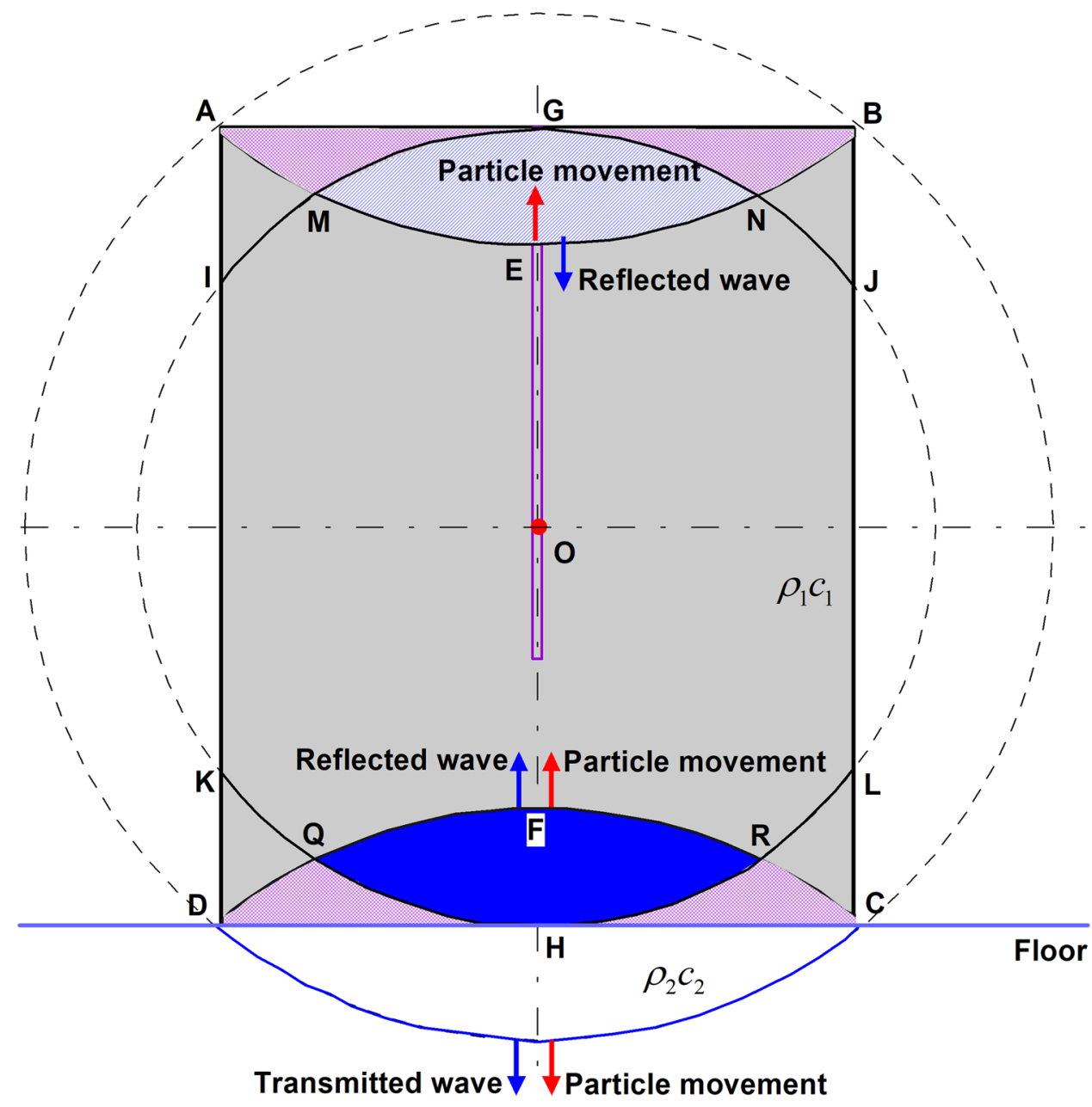

an increasing time, there will be only the two reflected waves in which the particles move upward, as shown in Fig. 9.

At the moment shown in Fig. 9, the end of the P-wave from the detonation is arriving at the corners $A, B, C$, and $D$ of the model, and the whole P-wave from the detonation has already passed over the model while only the two reflected waves are propagating in the model. The front and the end of the reflected wave from the top of the model are indicated by $E F$ and $A B$, respectively. The front and the end of the reflected wave from the bottom of the model are indicated by $I J$ and $D C$, respectively. At the same time, both reflected waves from the top and the bottom move to each other. Notice that all particles in both reflected waves move only upward, as shown in Fig. 9. Since this process will continue with an increasing time (i.e. the two waves will travel up and down in the specimen many times), the model will be thrown up until the maximum height. Then due to the gravitation, the model will finally fall down and land on the floor. After then, the model may bounce up again if it is not disassembled completely, as happened in S2 mentioned above.

\subsection{Characteristic Impedance of the Floor Material Smaller Than That of the Model One}

This case is shown in Figs. 10 and 11 where $\rho_{2} c_{2}<\rho_{1} c_{1}$. This case can be found in model blasting, for example, as a model is placed on wood or similar material whose impedance is smaller than specimen's impedance. Similar to the case in Sect. 4.1, the wave reflection from the lateral surfaces will be not considered in the following analysis, so that we focus on the stress wave analysis in the vertical direction. from the detonation is arriving at the corners of the model, and its end coming to the position where the smaller dashed circle is located. There are two reflected waves from $\mathrm{AB}$ and $\mathrm{DC}$. Now look at the first reflected wave from $\mathrm{AB}$ in the area enclosed by AGBNEMA in the upper part of the model. This wave with amplitude $\sigma_{A B}$ and particle velocity $v_{A B}$ is formed by the reflection of the original wave with amplitude $\sigma_{I}$ and particle velocity $v_{I}$. Similar to the analysis in Sect. 4.1, we get:
At the moment shown in Fig. 10, the front of the P-wave 
Fig. 9 Stress wave propagation in the model-floor system when the end of the P-wave just arrives at the corners of the model under the condition $\rho_{2} c_{2}>\rho_{1} c_{1}$

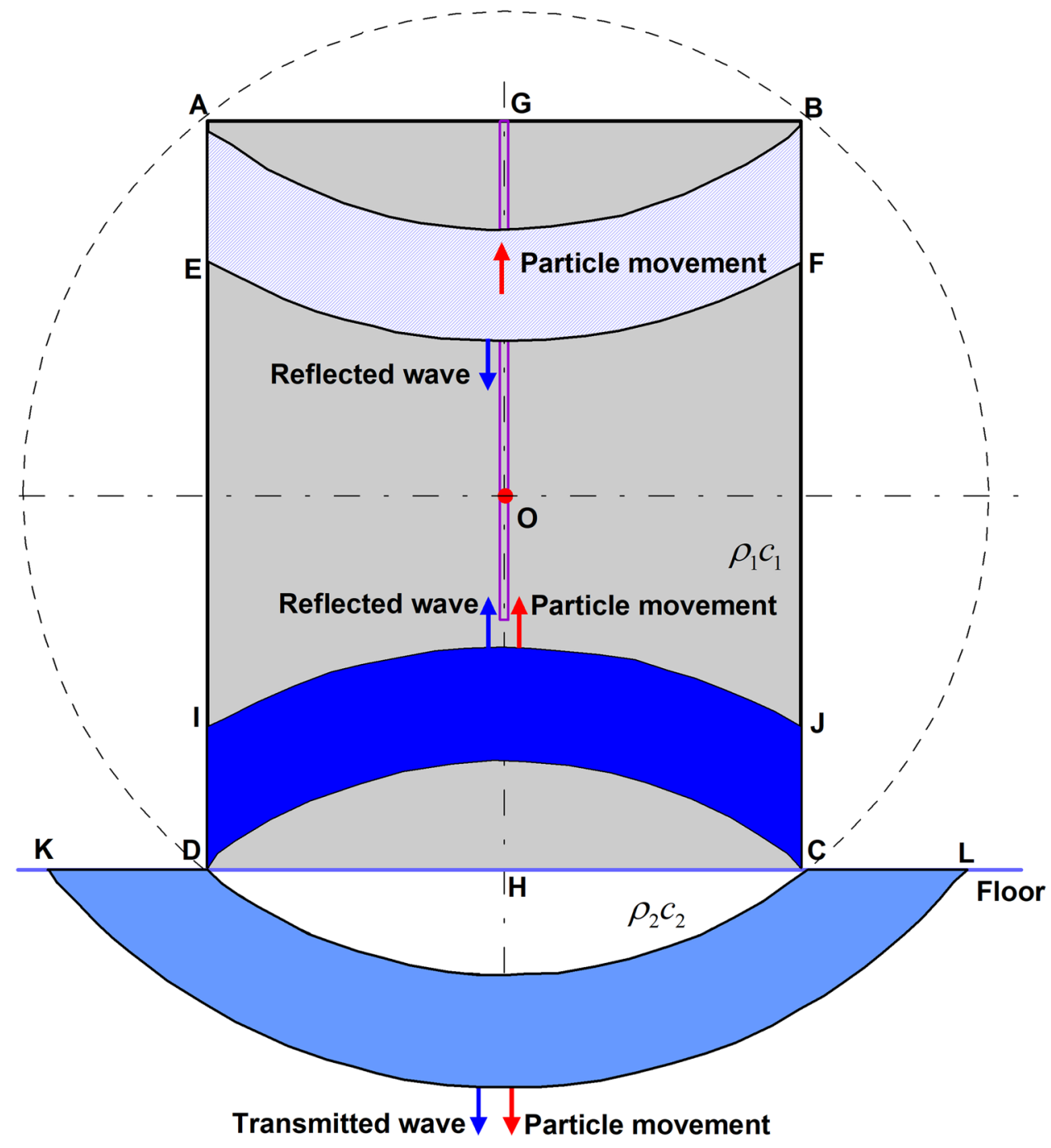

$v_{D C}=-R_{12} v_{I}$.

This result indicates that the reflected wave from DC enclosed by DQFRCHD is a tensile wave and the particles in this wave move downward, in the same direction as the original compressive wave. Because the wave reflected from $\mathrm{AB}$ is a full reflection but the wave from $C D$ is a partial reflection, the value of $v_{A B}$ is greater than that of $v_{D C}$. As a consequence, the superposition of the two reflected waves, i.e. the two areas AGBNEMA and DQFRCHD, results in that the particles may move upward in the model. However, the movement (height and velocity) of the model will be much small, compared with that in the case of $\rho_{2} c_{2}>\rho_{1} c_{1}$. Thus, this is different from the case in Sect. 4.1.

$-1<R_{12}<0$,

$\sigma_{D C}=R_{12} \sigma_{I}$ 
Fig. 10 Stress wave propagation in the model-floor system when the front of the P-wave just arrives at the corners of the model under the condition $\rho_{2} c_{2}<\rho_{1} c_{1}$. The end of the P-wave is arriving at $I, G, N, J$, $L, H$, and $K$

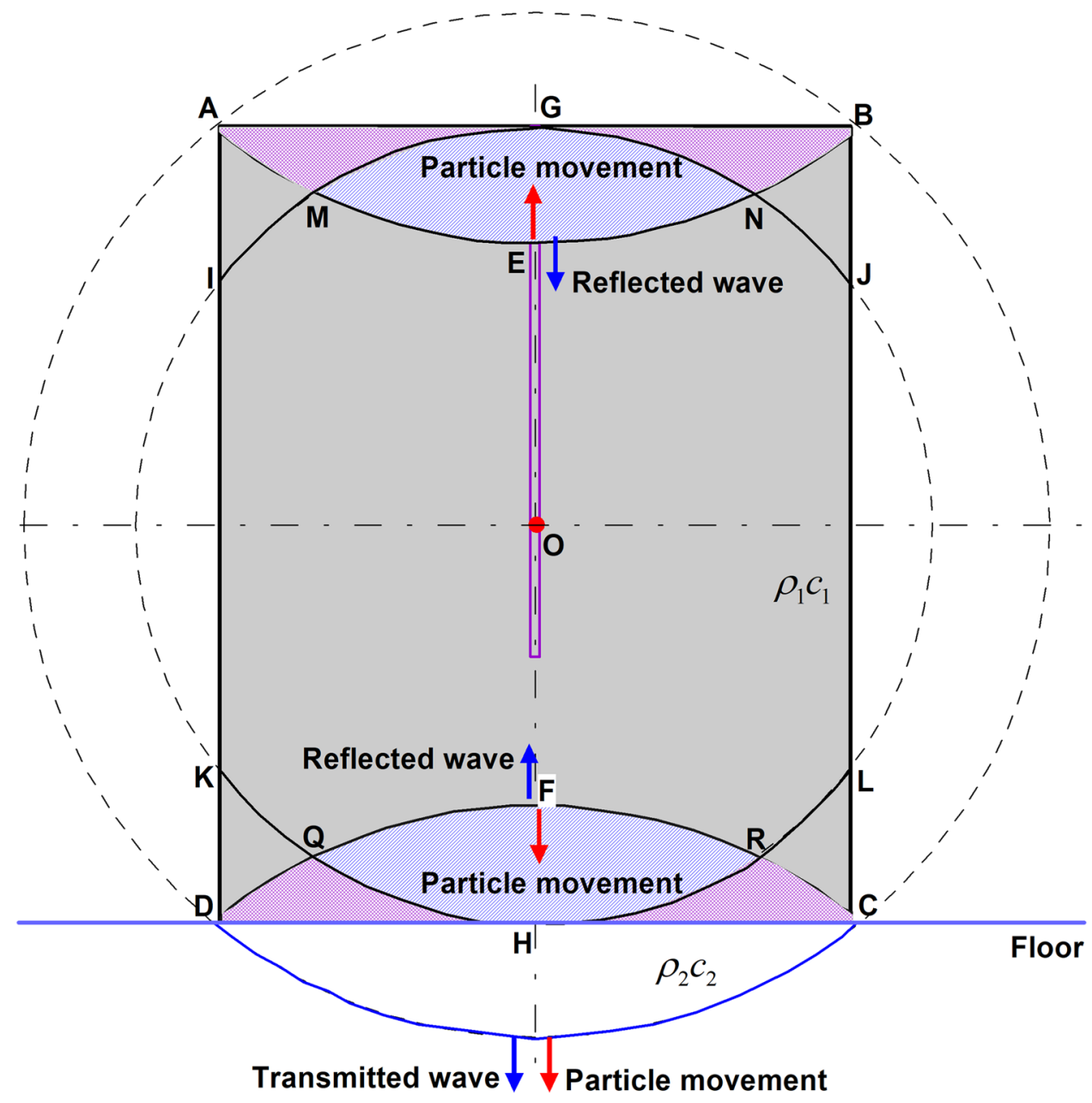

\subsubsection{Characteristic Impedance of the Floor Material Equal to That of the Model One}

As the characteristic impedance of the floor material that is very thick or deep is equal to that of the model, wave reflection from the interface between the model and the floor does not exist. In reality, the floor of an explosion chamber is often made of steel. To reduce and postpone the reflection wave from the floor, extra models or specimens may be placed on the floor and the blast model can be placed on the extra models, similar to the placement of S3 and S4 in this study.

\section{Discussion}

As a model blast is carried without high-speed camera, the whole blasting process is invisible. Accordingly, it is unknown whether the model is thrown or not during blasting. If model blasts aim to study detonation behavior or measure detonation pressure, specimen placement may not markedly affect the measurement since the detonation will be over before the model is thrown. However, the placement will influence rock fragmentation in the late stage of blasting. Therefore, specimen placement should be considered in all kinds of model blasts. No matter which kind of specimen placement is to be used, a simple stress wave analysis, as conducted in this paper, is needed before model blasting so that the effect of specimen placement on blast result can be estimated and limited to a small range.

In two model blasts of S1 and S2, both rock specimens were thrown up during blasting. This phenomenon is consistent with the stress wave analysis in this paper. Thus, in model blasts, to avoid such throw, the case-the characteristic impedance of the whole rock specimen is markedly smaller than that of the base material such as a steel floorshould be avoided.

In two other model blasts S3 and S4, the throw of the models was nearly not observable. This is also consistent with the stress wave analysis in this paper since the characteristic impedances of the models and the three rock blocks are equal to each other. In this case, there is no reflection wave from the interface between the models and the blocks, although the initial compressive wave from blasting was 
Fig. 11 Stress wave propagation in the model-floor system when the end of the P-wave arrives at the corners of the model under the condition $\rho_{2} c_{2}<\rho_{1} c_{1}$

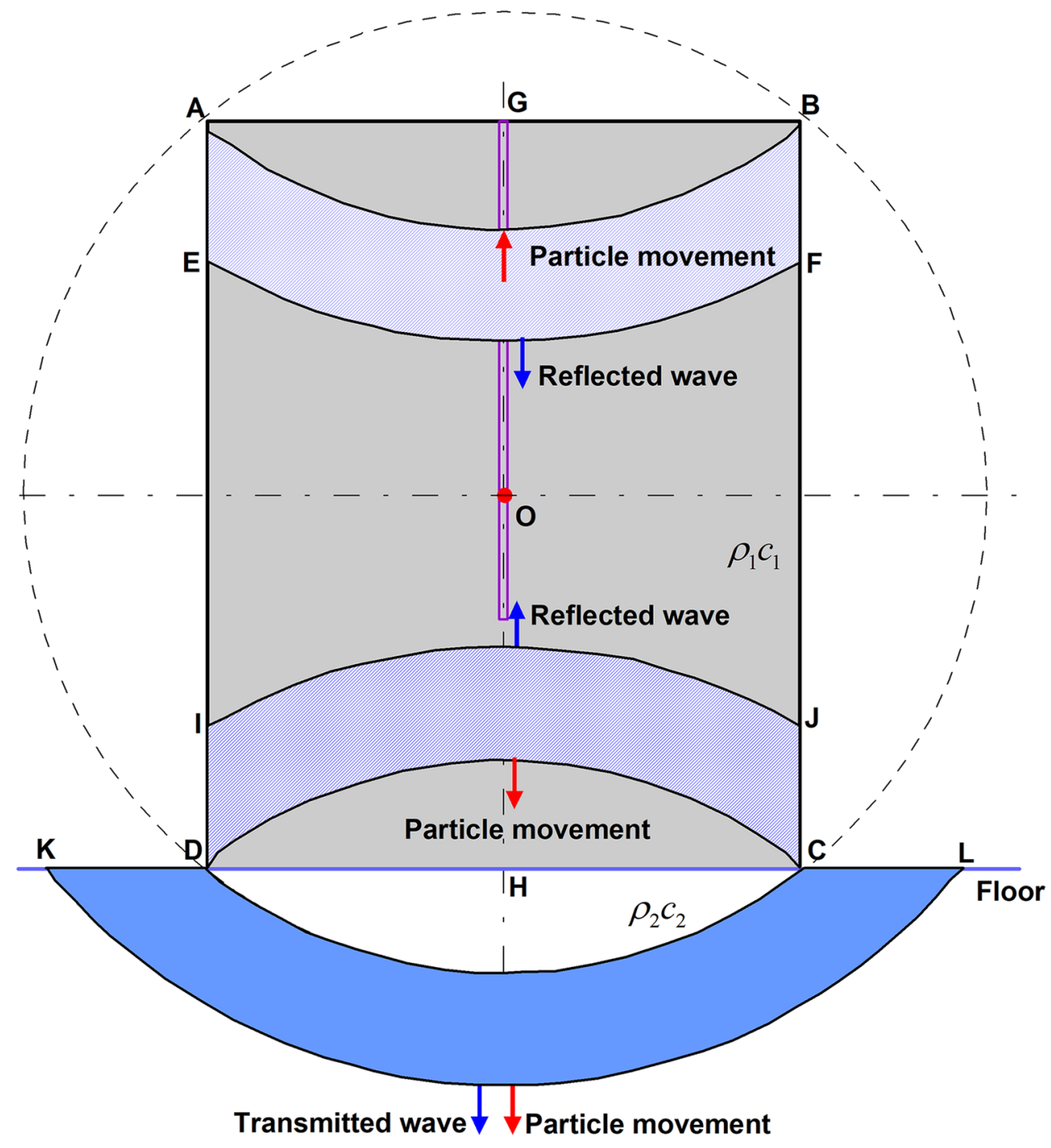

certainly reflected back to the blocks when it arrived at the floor. However, this took a time of $600 \mu$ s in the case of S3 and S4, as analyzed earlier. At that moment, main cracks had been created by blasting. In addition, the attenuation of stress waves in the rock mitigates the effect of the reflected wave from the floor on rock fracture by blasting. Therefore, this placement should be suitable for model blasts, especially for the blasts aiming at accurate measurement on rock fracture. This placement has been employed by Chi et al. (2019a, b, c) and Zhang et al. (2020a, b) for both cylindrical and cubic rock models with a small amount of explosive charge. When this placement is used in blasts with high specific charge, the block immediately beneath the rock specimen, may be broken by blasting. If this happens, the fragments from the rock specimen and the fragments from the block must be separated after blasting. Otherwise, it is difficult to get fragmentation result.

In case a high specific charge must be employed in model blasting, a rock specimen can be placed on a material whose impedance is smaller than the impedance of the rock specimen. This placement is the case analyzed in Sect. 4.2. As analyzed there, specimen throw may still exist in this case but the throw may be small or it may be neglected, depending on the difference between the impedances of the rock specimen and the material beneath the specimen. A greater difference will result in less throw. Accordingly, wood is often chosen as the material placed beneath a rock specimen. This placement has been used in a number of model blasts with high specific charges (e.g. Zhang et al. 2020a, b).

Figure $6 \mathrm{~b}$ indicates that the peak velocities during the first two upward movements are larger than the ones in the first two landings. The main reason might be the error in velocity measurement which is associated with the frame rate and resolution of the high-speed imaging. This error is $\pm 0.29 \mathrm{~m} / \mathrm{s}$ in $\mathrm{S} 1$ and $\pm 0.59 \mathrm{~m} / \mathrm{s}$ in $\mathrm{S} 2$ based on the measured data. This error can be also seen in Fig. 6b. To reduce this error, the frame rate and resolution of the high-speed imaging should be increased. Another possible reason 
might be that the mass of the whole specimen was possibly smaller than the original mass when the specimen landed since the small fragments from the crater in the top of the specimen probably would not fall together with the specimen. We can see that both peak landing velocities are higher than the two peak bounce velocities. However, the second reason needs more detailed model blasts to confirm.

Because of the limited quantity and condition of the model blasts in this study, a further study on the effects of the throw of a specimen on fragmentation are necessary by means of more model blasts. In the further study, it is recommended to use the same type of rock specimens (such as S3 and S4 in this study) but two different base materials, one with higher impedance (such as steel) than the rock specimens and the other with the same impedance as the rock specimens. Such further study may be also useful for multi-hole blasting in mining and tunneling, regarding rock fragmentation.

\section{Conclusions}

Based on the model blasts with stress wave analysis, the following conclusions can be drawn:

As the impedance of a rock specimen in model blasting is smaller than that of the ground material on which the specimen is placed, the specimen is thrown up. The throw-related kinetic energy is about $1 \%$ of the explosion energy in this study. Even though this percentile is small, the effect of this kinetic energy on rock fragmentation may not be ignorable. Thus, this placement should be avoided in model blasts.

There is no specimen throw during blasting as a rock specimen is placed on three same-rock blocks. In this case, no kinetic energy is induced by specimen throw. Therefore, this kind of specimen placement is recommended for model blasts.

If very high specific charge must be employed in model blasting, the recommended method for specimen placement will be difficult to use since the base material such as granite block beneath the specimen may be broken during blasting. In this case, the rock specimen can be placed on a material whose impedance is smaller than the impedance of the rock specimen so that specimen throw can be reduced. At the same time, a possible specimen throw should be estimated by stress wave analysis.

Funding Open access funding provided by University of Oulu including Oulu University Hospital.

\section{Declarations}

Conflict of interest The authors declare that there is no competing interest.

Open Access This article is licensed under a Creative Commons Attribution 4.0 International License, which permits use, sharing, adaptation, distribution and reproduction in any medium or format, as long as you give appropriate credit to the original author(s) and the source, provide a link to the Creative Commons licence, and indicate if changes were made. The images or other third party material in this article are included in the article's Creative Commons licence, unless indicated otherwise in a credit line to the material. If material is not included in the article's Creative Commons licence and your intended use is not permitted by statutory regulation or exceeds the permitted use, you will need to obtain permission directly from the copyright holder. To view a copy of this licence, visit http://creativecommons.org/licenses/by/4.0/.

\section{References}

Bergman OR, Riggle JW, Wu FC (1973) Model rock blasting—effect of explosives properties and other variables on blasting results. Int J Rock Mech Min Sci Geomech Abstr 10:585-612

Bhandari S (1979) On the role of stress waves and quasi-static gas pressure in rock fragmentation by blasting. Acta Astronaut 6:365-383

Brace WF, Walsh JB (1962) Some direct measurements of the surface energy of quartz and orthoclase. Am Miner 47:1111-1122

Chi LY, Zhang ZX, Aalberg A, Yang J, Li CC (2019a) Fracture processes in granite blocks under blast loading. Rock Mech Rock Eng 52:853-868. https://doi.org/10.1007/s00603-018-1620-0

Chi LY, Zhang ZX, Aalberg A, Yang J, Li CC (2019b) Measurement of shock pressure and shock-wave attenuation near a blast hole in rock. Int J Impact Eng 125:27-38. https://doi.org/10.1016/j. ijimpeng.2018.11.002

Chi LY, Zhang ZX, Aalberg A, Li CC (2019c) Experimental investigation of blast-induced fractures in rock cylinders. Rock Mech Rock Eng 52:2569-2584. https://doi.org/10.1007/ s00603-019-01749-0

Dally JW, Fourney WL, Holloway DC (1975) Influence of containment of the borehole pressures on explosive induced fracture. Int J Rock Mech Min Sci Geomech Abstr 12:5-12

Fickett W, Davis WC (2000) Detonation: theory and experiment. Dover Publications, New York

Field JE, Ladegaard-Pedersen A (1971) The importance of the reflected stress wave in rock blasting. Int J Rock Mech Min Sci Geomech Abstr 8:213-326

Fourney WL (2015) The role of stress waves and fracture mechanics in fragmentation. Blast Fragm 9(2):83-106

Fourney WL, Dally JW, Holloway DC (1974) Stress wave propagation from inclined line charges near a bench face. Int J Rock Mech Min Sci Geomech Abstr 11:393-401

Fourney WL, Barker DB, Holloway DC (1981) Model studies of explosive well stimulation techniques. Int J Rock Mech Min Sci 18(2):113-127

Fourney WL, Dick RD, Wang XJ, Wei Y (1993) Fragmentation mechanism in crater blasting. Int J Rock Mech Min Sci Geomech Abstr 30:413-429

Fourney WL, Bihr S, Leiste U (2006) Borehole pressures in an air decked situation. Int J Rock Blast Fragm 10(1):47-60

He C, Yang J, Yu Q (2018) Laboratory study on the dynamic response of rock under blast loading with active confining pressure. Int J Rock Mech Min Sci 102:101-108 
Johansson D, Ouchterlony F (2013) Shock wave interactions in rock blasting - the use of short delays to improve fragmentation in model-scale. Rock Mech Rock Eng 46:1-18

Johnson W (1972) Impact strength of materials. Edward Arnold, London

Katsabanis P, Tawadrous A, Braun C, Kennedy C (2006) Timing effects on the fragmentation of small scale blocks of granodiorite. Int J Rock Blast Fragm 10(1):83-93

Katsabanis P, Omidi O, Rielo O, Ross P (2014) Examination of timing requirements for optimization of fragmentation using small scale grout specimens. Blast Fragm 8(1):35-53

Kolsky H (1963) Stress waves in solids. Dover Publications, New York

Langefors U, Kihlström B (1963) The modern technique of rock blasting. Wiley, New York

Liu F, Guo Z, Lv H, Cheng Z (2018) Test and analysis of blast wave in mortar test block. Int J Rock Mech Min Sci 108:80-85. https://doi.org/10.1016/j.ijrmms.2018.06.003

Mao X, Ma Y, Liu X (2020) Deformation characteristics and electrical resistivity response of soft coal under blast loading. Geotech Geol Eng 38:1205-1216. https://doi.org/10.1007/s10706-019-01082-x

Moser P, Grasedieck A (2004) Rock specific breakage energy functions derived from lab scale blast experiments. In: International society of Explosives Engineers, 2004G, vol 2

Nie S, Olsson M (2001) Study of fracture mechanism by measuring pressure history in blast holes and crack lengths in rock. Bergsprängningskommitten Stockholm 2001:240-248

Nie S, Deng J, Ouchterlony F (2000) Expansion work of an emulsion explosive in blast hole-measurement and simulation. SveBeFo Report 48 (in Swedish)

Onederra IA, Furtney JK, Sellers E, Iverson S (2013) Modelling blast induced damage from a fully coupled explosive charge. Int J Rock Mech Min Sci 58:73-84

Ouchterlony F, Nyberg U, Olsson M, Bergqvist I, Granlund L, Grind H (2004) Where does the explosive energy in rock blasting rounds go? Sci Technol Energ Mater 65(2):54-63

Rustan A (1995) Controlled fragmentation and contours in rock blasting - theoretical and technical approaches. Luleå University of Technology, Doctoral Thesis, 170D
Sanchidrián JA, Pablo S, López LM (2007) Energy components in rock blasting. Int J Rock Mech Min Sci 44:130-147

Santhanam AT, Gupta YP (1968) Cleavage surface energy of calcite. Int J Rock Mech Min Sci 5:253-259

Sun C (2013) Damage zone prediction for rock blasting. PhD thesis, Department of Mining Engineering, The University of Utah

Tilert D, Svedbjörk G, Ouchterlony F, Nilsson B, Temun A, Mattsson L (2007) Measurement of explosively induced movement and spalling of granite model blocks. Int J Impact Eng 34:1936-1952

Wang LL (2007) Foundations of stress waves. Elsevier, Oxford

Yang R, Ding C, Yang L, Lei Z, Zheng C (2019) Study of decoupled charge blasting based on high-speed digital image correlation method. Tunn Undergr Sp Technol 83:51-59. https://doi.org/10. 1016/j.tust.2018.09.031

Zhang ZX (2016) Rock fracture and blasting: theory and applications. Butterworth-Heinenmann/Elsevier, Oxford

Zhang ZX, Hou DF, Guo Z, He Z (2020a) Laboratory experiment of stemming impact on rock fragmentation by a high explosive. Tunn Undergr Sp Technol 97:103257. https://doi.org/10.1016/j. tust.2019.103257

Zhang ZX, Hou DF, Guo Z, He Z, Zhang Q (2020b) Experimental study of surface constraint effect on rock fragmentation by blasting. Int J Rock Mech Min Sci 128:04278. https://doi.org/10. 1016/j.ijrmms.2020.104278

Zhang ZX, Chi LY, Qiao Y, Hou DF (2021) Fracture initiation, gas ejection and strain waves measured on specimen surfaces in model rock blasting. Rock Mech Rock Eng 54:647-663. https://doi.org/ 10.1007/s00603-020-02300-2

Publisher's Note Springer Nature remains neutral with regard to jurisdictional claims in published maps and institutional affiliations. 